\title{
Si usted tiene la más mínima duda... escoja un artesano
}

\author{
Patricia Pitcher*
}

En el curso de varios años, he observado desde adentro una empresa internacional de servicios financieros con activos que alcanzan decenas de miles de millones de dólares y sucursales en varios continentes. Después de haber asistido a innumerables sesiones ordinarias y extraordinarias de comités y de consejos, me pareció claramente que uno encontraba tres grandes tipos de personas -el artista, el tecnócrata y el artesano- entre los quince jefes de dirección del grupo y de sus grandes divisiones. Cada uno de los tres tipos de dirigentes hablaba un lenguaje diferente y tenía intereses y prioridades variadas. El uno quería que la empresa "conquistara" el mundo, al menos vastas partes del mundo; el otro que "perfeccionara" lo que ya hacía; y el tercero, que pusiera a punto sus "sistemas" y generara utilidades. Los dos primeros grupos deseaban igualmente alcanza utilidades, pero su concepción de la manera de realizar difería enormemente de la del tercero.

* Profesora de Administración. Escuela de Altos Estudios Comerciales. Quebec-Canadá.

Traducción del francés: Barthélemy Marchi Soto. 


\section{EL TIPO IDEAL DE "ARTISTA"}

Como los artistas no son ajenos al liderazgo visionario, el campo del arte es de un gran auxilio para comprender el carácter del "artista administrativo" y la naturaleza de su empresa. La civilización depende de la visión del artista; nos fuerza a cambiar, a menudo de mala gana, nuestras maneras de ver. Su visión emana no de una necesidad consciente de rebelión, sino de su carácter. Es sensible al mundo externo e interno; vive, precariamente, en la frontera de los dos.

No basta dominar las técnicas de la administración moderna para ser un gran gestor. Pero $i$ eso quiere decir que los grandes artistas o los líderes visionarios son todos locos? ¡Pues bien! No, no exactamente. Ellos son "anormales" en el sentido en el cual una persona de 2.15 metros es anormal. Es en el campo emotivo que se diferencian de los otros, evidentemente igual de inteligentes, pero menos cretinos. Son anticonformistas, les gusta más que los otros la complejidad y el desorden y aprueban mucho mejor los tests de intuición. Son muy inclinados a la depresión, de una parte, o a la hipertimia -su contraria- de otra parte; o a una combinación cíclica de las dos -la ciclotimia. Los spleens de De Vinci eran fabulosos; los de Van Gogh, suicidas.

\section{¿Cómo SE RECONOGE UN ARTISTA?}

El "artista" administrativo se molesta con lo convencional y experimenta la necesidad de alejarse de ello. Eso se debe a su carácter, alterna entre dos periodos, de excitación y de depresión. En período de excitación, está lleno de ideas; a los ojos de los demás parece "intuitivo", "imaginativo", "imprevisible", "cambiante", "emotivo"; se diría que vive en un sueño.

"Genio administrativo", el artista es inventivo, intuitivo, gracioso, inspirador, excitante, emotivamente inestable, visionario, de humor cambiante, a veces solitario. Hombres aparentemente tan disparatados como Abraham Lincoln y Renée Léves que dan una idea de lo que es el artista. 


\section{EL TIPO IDEAL DEL "TECNÓCRATA"}

Para comprender mejor las especificidades del artista, es útil compararlo conel tecnócrata, definido como la persona que tiende "a hacer prevalecer las concepciones técnicas de un problema en detrimento de las consecuencias sociales y humanas". Si la característica principal del artista es poder navegar entre el consciente y el inconsciente, vivir en su frontera sin enfermarse, la del tecnócrata es la de ser incapaz de eso. Rollo May decía que el compulsivo teme tanto al inconsciente que deja zozobrar su conciencia en una "racionalidad árida, banal, vacía". Si el artista desafia las convenciones, el compulsivo se agarra a ellas, se conforma con ellas, las deifica. Tratando de anticiparse a la oleada del inconsciente, el compulsivo embrutece todo efecto. En general, esuda el dominio de sus emociones, la rigidez. Reich dice a propósito de los compulsivos que son "máquinas vivientes".

En general, el maníaco compulsivo tiene un interés muy preciso y a él se aferra; investiga y junta los hechos y los establece claramente, pero faltan a menudo los aspectos de la situación que le dan sabor e impacto. Así, los compulsivos parecen a menudo insensibles al "tono" de las situaciones sociales.

El juego no está a la orden del día en ellos. La espontaneidad está excluida. Son tercos y no sufren ninguna intrusión en sus planes, que están después de todo fundados sobre los "hechos". Su mecanismo de defensa es la intelectualización. Porque ahí muy a sus anchas con los detalles, los "hechos", hacen a menudo prueba de su virtuosidad técnica y de ingeniosidad -ahí reside la fuente de su poder. En gestión, pensemos en las realizaciones de Frederick Taylor, en sus análisis obsesivos de tiempos y movimientos, para comprender a la vez las virtudes y las dificultades de este tipo de carácter.

\section{¿Cómo SE RECONOCE UN TECNÓCRATA?}

Cerebral, austero, intransigente, resuelto, terco, meticuloso, a menudo brillante, dice querer dominar la "emoción" con la "razón", pero es una mentira. Las gentes sensatas colocan la razón en primera fila; el tecnócrata 
quiere, "apasionadamente", que la razón extirpe la pasión. Los hay de todas clases -de todas las tallas y de todas las apariencias. Están presentes en todas las instituciones y se comprometen con todo tipo de causa. No se les identifica por las causas que defienden, sino por la manera como las defienden.

Puedo ahora oler tecnócratas a cincuenta metros. Comienzo por sentirme incómoda, ligeramente irritada, me asfixio un poco cuando me encuentro uno. Poco a poco llego a formarme una idea y a dar un nombre a mis sentimientos. Lo oigo hacer una pequeña perorata y sé que nos toma a todos por unos imbéciles, que se cree el único poseedor de la verdad, la justicia y la moral. Parece "brillante", pero siento rigidez. Sé que su espíritu está cerrado. Debemos comenzar a mantener una sana desconfianza con respecto al epíteto "brillante". Es "intransigente", "terco", muy seguro de sí y despreciativo en cuanto al prójimo.

Cualquiera que sea el tema del orden del día, es posible que el tecnócrata tenga objetivamente razón. Porque es brillante, tiene a menudo razón, pero ahí no está el problema. La cuestión es que él sabe que tiene razón. Nunca se equivoca y los otros son simplemente demasiado estúpidos para darse cuenta. El tecnócrata no duda jamás, no se deja derribar jamás, tiene siempre una respuesta. Si el tecnócrata no está nunca deprimido, es que no duda jamás porque siempre encuentra alguien o algo para censurar. El tecnócrata es narcisista "yo no me equivoco; ellos se equivocan. ¿Cómo osan criticarme?" Es paranoide: "Soy gentil, son los otros los peligrosos". Es compulsivo, "soy lógico, ellos son emotivos". Los tecnócratas responden a la definición que da Oscar Wilde de un cínico; un hombre que sabe el precio de cada cosa, pero que no conoce el valor de ninguna.

\section{EL ARTESANO Y LA ARTESANÍA}

$\mathrm{Si}$, como dice Jung, las visiones del artista son "puentes lanzados hacia una orilla inexplorada", el artesano es aquel que construye los puentes y que procede siempre por etapas, de acuerdo al enriquecimiento lento, gradual de los conocimientos y de la técnica. La diferencia entre el arte y la artesanía sigue siendo objeto de vivos debates en la estética; la 
artesanía hace utilizar los "descubrimientos" del arte, los transforma, los perfecciona, los refina, los concreta, los moldea, los esculpe por la experiencia.

La artesanía se funda sobre usos y tradiciones, transmitidos de maestro a aprendiz en un sentido activo, físico, y no en clase o por un libro. No se puede "decir" cómo dirigir una organización. Estas disciplinas requieren prácticas, experiencia y un "conocimiento tácito".

La artesanía se funda sobre la práctica pero ésta no es solamente asunto de repetición. La práctica y el aprendizaje enseñan a hacer y a pensar al mismo tiempo; son ejercicios a la vez conceptuales y prácticos.

La artesanía lanza grandes desafíos al mundo moderno. El respeto de las prácticas de un arte exige la sumisión a la autoridad porque el oficio debe ser transmitido de maestro a aprendiz. La "formación en el taller" nos da una comprensión práctica del arte, que no puede reducirse a máximas. Estas últimas no pueden ser comprendidas, y mucho menos aplicadas, por quien no posee ya un buen conocimiento del arte.

Las escuelas de gestión exigen en general candidatos a maestría con un mínimo de experiencia porque sienten que sus "máximas" no pueden ser comprendidas, y mucho menos aplicadas, por cualquiera que no posea, de antemano, un buen conocimiento del arte. Sin embargo, ¿cuántas máximas no hemos oído en gestión? Y ¿cuántas veces esas "máximas" han sido utilizadas por gentes que no habían puesto jamás los pies en una empresa? Por último, como sociedad, no nos gusta casi nada la autoridad ni la tradición; tenemos por tanto muchos problemas con la artesanía.

¿Pero entonces qué pasa con el artesano en la organización? Por lo pronto, deberá ser paciente. Someterse a la autoridad supone una aptitud para renunciar temporalmente a su forma de hacer. Será posiblemente conservador, puesto que respeta la tradición. No se apartará fácilmente de los trucos del oficio. Las "máximas" disociadas de la "comprensión", que no pueden resultar sino de la experiencia, lo molestarán. Será responsable, sensible y dará prueba de buen juicio. Será honesto, leal y directo, amable y tolerante. 


\section{¿COMO SE RECONOCE UN ARTESANO?}

Consagrado, digno de confianza, honesto, sosegado, realista y prudente. Estas "cualidades" han caído en descréditos, en parte porque la modernidad no puede tolerar la autoridad, la disciplina, la tradición, que son las virtudes del artesano. Inteligencia sin brillo, sin pulido y sin destello. Principios bien sentados, franqueza, juicio, equilibrio. Es una persona de experiencia, bien informada, razonable, con un buen criterio; se ve venir el tecnócrata de lejos, pero respeta los "soñadores": "Las gentes de análisis se recogen con pala, pero no se compran los sueños".

¿Qué requieren las organizaciones? ¡Si usted tiene la más minima duda, es decir casi siempre, escoja un ... artesano! 